\title{
Vascular Ehlers-Danlos syndrome
}

INSERM

\section{Source}

INSERM. (1999). Orphanet: an online rare disease and orphan drug data base. Vascular Ehlers-Danlos syndrome. ORPHA:286

Ehlers-Danlos syndrome type IV, also known as the vascular type of Ehlers-Danlos syndrome (EDS), is an inherited connective tissue disorder defined by characteristic facial features (acrogeria) in most patients, translucent skin with highly visible subcutaneous vessels on the trunk and lower back, easy bruising, and severe arterial, digestive and uterine complications, which are rarely, if at all, observed in the other forms of EDS. 